\title{
Study on the Psychological Analysis of Youth's Passion Crime and Relevant Countermeasures
}

\author{
Shuang Zhang \\ Hainan Vocational College of Political Science and Law, Haikou Hainan, 571000, China
}

Keywords: Juvenile delinquency, Passion crime, Criminal psychology, Prevention countermeasures.

\begin{abstract}
With the rapid development of social economy and the improvement of living standards, the living conditions of the young is getting better and better, the individual consciousness is becoming stronger and stronger, and the phenomenon of passion crime is increasing. In terms of the physical and mental characteristics of young people, the teenagers' psychological fluctuation is great in the period of transition and physical development, and the latent factors of inducing passion crime exist. The youth passion crime has the characteristic of abrupt and different predictability, and because of the accurate factual judgment, the crime consequence is also easy to be uncontrollable. In this context, it is of vital importance to study the psychological dynamics of juvenile delinquency and to carry out accurate psychoanalysis to prevent juvenile delinquency.
\end{abstract}

\section{Introduction}

With the increasing juvenile delinquency, juvenile delinquency crime has become a hot topic in the theoretical and practical circles. It is an important direction for the modern juvenile delinquency to explore the psychological motivations of adolescent passion crimes and to carry out targeted prevention. In practice, the traditional crime research and prevention model focus on the discussion of criminal elements, but the psychological exploration of the crime is immature. In the process of teenage passion crime, psychological factors take an important leading role in exploring the psychological changes and dynamics of youth passion crime as well as preventing it.

\section{The characteristics of passion crime}

As a kind of crime, passion crime is not a specific crime in our country's criminal law, but a general designation of a kind of criminal acts, which often corresponds to premeditated crime. Passion crime is often in the state of the crime, so criminal behavior is unpredictable and sudden, criminal motives are often temporary, there is no clear criminal preparatory behavior, it's said that passion crime is a crime under the effect of strong emotions. It's an irrational behavior. In the psychological level, passion crime has a very deep psychological origin, that is, when people are under extreme emotional domination, it is easy for them to behave irrationally, and then to commit crimes and after the passion crime, the offender will generally have a penitent performance, many of which will also make remedial measures, but hey often can not effectively remedy because the crime results have been achieved, bringing about a strong social harmfulness.

From the nature of the crime itself, the passion crime is often sudden, transient and strong. The perpetrators are often in an unconscious state in the implementation of the process of passion crimes, which is an intense form of inner heart. The heart of the perpetrators is generally in a state of high tension or excitement. Under such extreme psychological domination, the offender often does not have sufficient psychological cognition, and there is no psychological understanding of the outcome of the crime, so the result of the crime is often uncontrollable. In the criminal environment, the perpetrators are often prone to extreme behavior, easy to pursue extreme criminal consequences, so the social harm is also relatively large. 


\section{The psychological factors leading to juvenile delinquency}

From the psychological level analysis, leading to juvenile passion crime factors is mainly multifaceted. Due to the growth environment or their own reasons, many young people have poor psychological quality especially after entering the campus or into society. Because they are unqualified to withstand, and lack the good family counseling and education, they are prone to extreme reactions in the face of setbacks and social problems, and make extreme moves, resulting in the crimes. Seen from the personality characteristics, the crime of juvenile passion crime often has more distinct characteristics and defects and juvenile passion criminals are often more extreme, and prone to self-centered, their interpersonal skills are often weak in dealing with interpersonal process, they do not want to actively communicate with others, there is a certain tendency to violence.

Seen from the external conditions, with the advent of the network society, young people that are accessible to multiple information opportunities continue to increase and often misread a lot of information, and vulnerable to pornography, violence and other adverse information. From the family point of view, many parents now ignore the psychological counseling and education for students. Besides, their education methods and methods are not targeted, due to the more rebellious adolescent teenagers that are prone to make extreme reactions. With the rapid development of social economy, young people are facing increasing pressure, on the one hand, relatively large learning pressure because the school is often easy to ignore ideological and political education, the students are prone to psychological problems, On the other hand, as the social competition continue to increase, many young people's survival pressure is weighing on, under such conditions, the gap between rich and poor, coupled with other factors, will also have a negative impact on young people's psychological and generate the dangers of crime, which will have a negative psychological impact and, in extreme cases, often lead to crime but for the effective diversion and education.

\section{The characteristics of youth passion crime}

Juvenile passion crime has a distinctive feature where emotional and rational imbalance led to the final crime. As a result, many crimes are sudden accompanied with the serious consequences in such extreme cases.

\section{Fast criminal ideas}

Unlike premeditated crime, juvenile delinquency has the characteristics of criminal idea. Because there is no pre-crime preparation and premeditated behavior, juvenile passion crime is mostly made by temporary stimulation of the perpetrators in the sudden extreme emotional state who lose self-control ability and whose goes to another extreme, and then make passionate criminal behavior. In such psychological dynamics, youth passion crime is too strong to prevent in advance, so the social harm is relatively large. With the emergence of young criminal behavior, it also causes more serious consequences.

\section{Quick criminal action}

From the crime process, juvenile delinquency crimes are often quick, due to the extreme emotional control of criminal behavior, juvenile passion crime is often very violent and sudden, and the crime process is very short and rapid and the whole process of crime are in an extremely intense state of emotional venting. Because there is no stage of crime preparation, the youth passion crime is often a temporary feature and the whole process of crime is not only difficult to prevent, but also difficult to stop.

\section{Cruel criminal means}

As teenagers are furious, and lacking in the awareness of the consequences and behavior of the crime, young people are generally fighting and hurting others characterized with the quick personal violence crimes.[3] In such circumstances, juvenile passion is often a very convenient means of crime, and the consequences are difficult to make an accurate prediction. 


\section{Serious consequences of the crime}

From the consequences of youth passion crime, they are often prone to serious consequences. Throughout the typical phenomenon of teenage passion crimes, they often have serious consequences, whether it is Yang Jia case or Ma Jiajue case, causing very serious consequences. Because the young passionate criminals are lacking in rational knowledge and emotional control in the process, the teenagers often pursue the extreme of the consequences of crime, which is likely to bring about serious consequences including a large number of personal property casualties.

\section{The psychological prevention of adolescent passion crime}

After analyzing the psychology of teenage passion crime, it is necessary to discuss the psychological prevention countermeasure of teenage passion crime. Mental defects resulting in the phenomenon of youth crime is an important reason in such circumstances and the youth passion crime should be given full attention to understand its characteristics whether it is family, campus or society, and there are targeted measures to resolve and prevent activities of crime in order to reduce the number of teenage passion crimes for the sake of healthy growth of young people to create a good environment.

\section{Widespread universal access to mental health knowledge}

In order to prevent the youth passion crime, we should popularize and preach the knowledge of mental health. From the youth's own characteristics, because of less social experience and immature physical and mental growth, they are lacking in necessary mental health knowledge. Under such conditions, it should firstly start from the psychological point of view to carry out the crime prevention work for the youth. From the family's point of view, to create a good environment for young people to grow up, do not give too much pressure on young people and to respect the personal growth of young people opinion. The school should provide psychological counseling courses for teenagers, help youngsters to construct healthy psychological system through correct guidance, form correct world outlook, personal view, values, and improve the ability of psychological cognition and self grooming. In the aspect of mental health guidance, we should improve the pertinence and scientific education, and choose the way of psychological education for teenagers. Because the teenagers are rebellious and the psychological education provided by the school is often contradictory, the school should pay attention to the times and science, take more cases and other educational models, improve the participation degree and the sense of generation of psychological education, and let more youngsters integrate into the mental health system and realize the goal of mental health education in the course of carrying out psychological education and dredging, .

It is not an empty slogan to carry out mental health education and prevent the youth passion crime, but it is necessary to innovate education mode, change educational concept, optimize education method, adopt the mode of combining theory teaching with case teaching, and promote the prevention effect of youth's passion crime. At the same time, we should strengthen the legal concept education work, let the young people know and understand the law, to recognize the consequences of their own criminal acts, to avoid the occurrence of passion crime phenomenon.

\section{Focus on humanistic care and psychological guidance}

To carry out the prevention work of youth Passion crime, we should do a good job of humanistic care and psychological guidance. From the view of content and nature, it is generally believed that humanistic solicitude originated from Europe, appeared from the Renaissance, and stressed that the attention to the individual was a consciousness of human civilization and a manifestation of high civilization. The humanistic care concept is applied to the youth's passion crime prevention, which is emphasized to meet the diversified needs of the youth and to improve the pertinence of crime prevention. In the traditional youth passion crime prevention work, the teenagers individuality demand and the individuality difference are often neglected, but the universal education method is adopted instead, lacking in respect for adolescent individuals. Under the guidance of humanistic care 
education idea, the youth's passion crime prevention work emphasizes the promotion of the individuality liberation and individuality development of the youth, and promotes the freedom and vigor of the youth, thus realizing the overall promotion of the ideological and moral level.

As a psychological vocabulary, psychological guidance has been widely applied in the field of education in recent years, especially in the field of youth passion Crime prevention, which can dissolve the inner perplexity of youngsters, guide the healthy growth of youngsters and establish a healthy world outlook, Outlook on life and values. In recent years, with the development of social economy, all kinds of social thoughts have come into being, which have produced a great impact on the youngsters in the face of the outside world and it is difficult for young people to maintain peace of mind. The psychological guidance work can help young people to solve the real life problems, guide the young people to form a positive, healthy, sunny mentality, improve the comprehensive mental health level, develop a healthy personality and to achieve adolescent passion crime prevention goals.

\section{Focus on interpersonal communication guidance and education}

To prevent youth passion crime, we should pay attention to the guidance and education of interpersonal communication, and establish the correct concept of making friends. In the face of unfamiliar environment, the young people who is full of expectations is filled with apprehension at the same time. They need help from classmates and friends, but how to communicate is a difficult problem in their lives. First of all, in the era of high information, micro-BO, micro-letters become known to the young where they are increasingly dependent on mobile phones. Many young people are addicted to network communication and by virtue of this virtual form of communication, they play the role of themselves in the virtual world to obtain the sense of self-satisfaction whose drawbacks are evident including weakening the ordinary real life of interpersonal communication. It's often the case that they are wordless when they are gathered together. Each person, with the mobile phone in his/her hand, communicate less with others, so it is difficult to form good interpersonal relations. Under such conditions, teenagers are apt to lose basic communicative ability, their character tends to be extreme, and they tend to produce passionate criminal behavior.

In addition, many young people choose friends with a certain purpose, and they are willing to meet the rich and powerful people or please them to obtain their help, eager, utilitarian, lack of sincere interaction between friends to worsen the relationship, make it disharmony, discord. In such a communication environment, it is easy to contaminate bad habits, leading to the weakening of self-control ability, and thus the crime phenomenon. Therefore, it is necessary to guide the youngsters to establish the correct view of making friends mainly through the network communication education, to help the young people realize the importance of the real communication, to teach them the way of real communication, so that they can form a good interpersonal relationship and deal with interpersonal relationships properly.

\section{Conclusion}

To sum up, young people inner fluctuations and greater changes in the ability to control the psychological dynamics is relatively weak in the physical and mental growth and transformation of the critical period. In such circumstances, it is easy to produce passion phenomenon. It is inseparable from the deep analysis of the psychology and growth characteristics of juvenile delinquency. By deconstructing the psychological dynamics and characteristics of teenage passion crimes, we can carry out preventive measures to enhance the effect of crime prevention and create a healthy and happy growth for young people. good environment.

\section{References}

[1] Lu Xiaotong. Psychological Analysis of Teenagers' Passion Crime and Countermeasures, Legal world, 2016(6):113-113. 
[2] Yu Jingting, Wangfang. A Theoretical Analysis of the Youth's Passion Crime in China, Reform and Openness, 2013(14):11.

[3] Liu Jing. Study on the Role of Ideological and Political Education in Controlling Juvenile Passion Crime, Theoretical research on Urban Construction (electronic version),2012(20).

[4] Wei Dongjie. Analysis of Psychological Causes of Teenagers' Passion Crime, Science Herald, 2015,(21):165-165.

[5] Zhou Aili. Psychological analysis and prevention of juvenile Passion crime, Chinese E-Commerce, 2014(1):255. 